\title{
The Interaction of Large Bowel Microflora with the Colonic Mucus Barrier
}

\author{
Jeffrey P. Pearson and Iain A. Brownlee \\ Institute for Cell and Molecular Biosciences, Medical School, Newcastle University, Newcastle upon Tyne NE2 4HH, UK \\ Correspondence should be addressed to Jeffrey P. Pearson, j.p.pearson@ncl.ac.uk
}

Received 6 May 2010; Revised 14 July 2010; Accepted 4 August 2010

Academic Editor: Dirk Haller

Copyright ( $) 2010$ J. P. Pearson and I. A. Brownlee. This is an open access article distributed under the Creative Commons Attribution License, which permits unrestricted use, distribution, and reproduction in any medium, provided the original work is properly cited.

\begin{abstract}
The colonic mucus barrier is the first line of defence that the underlying mucosa has against the wide range of potentially damaging agents of microbial, endogenous, and dietary origin that occur within the colonic lumen. The functional component of mucus is the secreted, polymeric glycoprotein mucin. The mucus barrier can either act as an energy source or a support medium for growth to the intestinal microflora. The mucus barrier appears to effectively partition the vast number of microbial cells from the underlying epithelium. The normal functionality and biochemistry of this mucus barrier appears to be lost in diseases of the colorectal mucosa. Germ-free animal studies have highlighted the necessity of the presence of the colonic microflora to drive the maturation of the colonic mucosa and normal mucus production. A number of by-products of the microflora have been suggested to be key luminal drivers of colonic mucus secretion.
\end{abstract}

\section{Background}

The colonic mucosa is constantly exposed to a wide range of luminal agents that have the potential for either mucosal damage, or mucosal protection. These luminal agents can be of microbial, dietary or endogenous origin. "Normal" colonic transit time varies widely in humans but within physiological boundaries would be between 24 and 48 hours, in comparison to transit through the upper GI tract which occurs within a few hours $[1,2]$. Therefore, there is a longer exposure time of the colonic mucosa to luminal agents than to the underlying tissues of other areas of the gut. In addition, due to the role of the colon in the salvage of unabsorbed nutrients and absorption of fluid [3], these luminal agents will be concentrated (particularly in the distal bowel), resulting in further increases of mucosal exposure to these agents. While removal of water from the faecal bulk is likely to reduce the diffusion of agents from the majority of the faecal cross-section, direct contact will still occur between the mucus and the outer surfaces of the colonic luminal contents.

The large bowel also plays host to approximately $10^{13}$ bacteria and other micro-organisms [4] and is thought to include over 500 bacterial species [5]. As such, changes to the prevalent species within the microfloral population or to microfloral functioning and output within the bowel are likely to be intimately linked with colorectal health and disease [6]. While digestion per se does not tend to occur in the colon, the colonic microflora acts to degrade dietary fibre and/or other dietary factors that escape digestion to produce further agents that could either harm or protect the underlying mucosa.

The colonic mucus barrier is the first line of defence the underlying mucosa has against the myriad of damaging agents that occur within the colonic lumen [7]. The colonic mucus barrier also acts to greatly reduce the shear stress caused by the passage of the luminal bolus along the colon [8]. This barrier can also act as an energy source or as a niche for bacteria within the large bowel $[9,10]$. Despite the relatively high potential for luminal exposure, previous studies in healthy humans suggest that bacteria do not routinely associate with the colonic mucosa and only occur at the luminal side of the intestinal mucus layer [11]. The remainder of this paper will focus on current evidence for how the interplay between microflora and mucus may be a key factor in mucosal health and disease and will also 
highlight what areas of research may be considered in the future to further understanding of this topic.

\section{Colonic Mucus Production and Secretion}

Mucus acts to protect most mucosal surfaces in the gut, airways, and urinogenital tract. The main functional component of mucus is mucin. Disulphide bridges between cysteine-rich areas towards the $\mathrm{C}$ - and $\mathrm{N}$-termini of the mucin backbone act to endow mucus with its characteristic viscoelastic gel properties. Up to $85 \%$ of the mucin molecule is oligosaccharide side chains by weight. The terminal sugars of these side chains are believed to play a crucial role in the adhesion of mucins to different bacterial cells (e.g., $[12,13])$. Changes in both the MUC gene product and glycosylation patterns are believed to be associated with the onset or development of colonic mucosal diseases, such as colorectal cancer and inflammatory bowel disease (IBD) [14].

In humans, there are five polymeric, secretory mucin gene products that are currently known, MUC2, MUC5AC, MUC5B, MUC6 [15], and MUC19 [16]. These genes for MUC2, MUC5AC, MUC5B, and MUC6 are all expressed from the same chromosome locus (11p15.5) [17]. Throughout the small and large intestine, MUC2 is the predominant mucin gene product [18]. Within the mammalian colon, mucins are highly negatively charged, due to the presence of ester sulphate and terminal sialic acids [19]. Reduction of this negative charge in secreted mucins is generally believed to be associated with colorectal disease onset and progression $[20,21]$.

Following transcription, mucin gene products are firstly $\mathrm{N}$-glycosylated and dimerise (through cysteine-rich regions at the C-terminal of the mucin backbone) in the rough endoplasmic reticulum [22]. This N-glycosylation is also believed to be important in the subsequent transfer of mucins into the Golgi apparatus [23]. Within this compartment, mucins are O-glycosylated [24], prior to $\mathrm{N}$-terminal oligomerisation [25]. Mucin granules are subsequently packaged tightly due to the presence of high levels of calcium ions [26]. Recent studies in this area have noted that the granules of the secreted gel-forming mucin MUC5B (isolated from saliva) appeal to each contain somewhere in the region of 50-100 sub-units of mucin, organised into 10-15 isolated polymers, which are believed to represent the grouping of cysteine-rich C and N-terminal regions [27]. Granules rapidly expand from a diameter of approximately $350 \mathrm{~nm}$ to around $1000 \mathrm{~nm}$, with the end products being polymeric chains of 4-8 mucin subunits [27]. Upon their release, mucin molecules become disassociated from the calcium ions and are believed to unfurl in the presence of the aqueous milieu. It has previously been suggested that the rheologically thick mucus secretion seen in cystic fibrosis is a result of incomplete hydration of mucin granules, possibly as a result of defective $\mathrm{HCO}_{3}{ }^{-}$transport $[28,29]$.

The pathways associated with mucus production are highlighted in Figure 1. Triggering of mucin synthesis or secretion, alongside goblet cell/epithelial proliferation and crypt lengthening, may be mediated by a spectrum of neurohumoral, local, and immune factors. Total mucin output from the colon can be elevated as a result of increased mucin biosynthesis, exocytosis rates, and total goblet cell numbers.

Increased MUC2 mRNA was noted by quantitative RTPCR analysis in human colon cancer cell lines in response to a single stimulation with IL-4 (approximate two-fold increase in comparison to baseline), IL-13, and TNF- $\alpha$ (c.2.5fold increase in MUC2 mRNA) via MAP kinase pathways [30]. N-glycosylation of MUC2 monomers appears to be necessary to drive further processing of mucin subunits, and is a required step prior to passing into the Golgi apparatus [23]. The expression of mRNA of 3 out of 8 tested isoenzymes governing O-glycosylation of mucins (polypeptide $\mathrm{N}$ acetylgalactosaminyltransferases) in a colon cancer cell line, was also noted to be upregulated by the Th2 cytokine IL-4, resulting in increased incorporation of GalNAc into mucin oglycans [31]. Within a random mutagenesis model of murine colitis, an increase in both the amounts of Th1 and Th2 cytokines secreted by cultured leukocytes and the increased leukocyte numbers within mesenteric lymph nodes were associated with the accumulation of an unglycosylated Muc2 oligomers precursor in the Golgi apparatus. Within the same study, unglycosylated MUC2 precursors were also noted to occur in human ulcerative colitis, even in noninflamed intestinal tissue [32]. In Il-10-deficient mice, total Muc2 output and synthesis was reduced in germ-free animals. Upon application of a commensal microflora, there was a significant reduction in mucin sulphation compared to sulphation in the germ-free animal [33]. This evidence would therefore suggest a major role for Th2 cytokines in the control of mucin synthesis.

In studies on isolated colonic crypts from macroscopically normal tissues, it was noted that goblet cell exocytosis, as assessed by differential interference contrast microscopy, occurred during cholinergic and histamine-mediated stimulation [34]. Within these studies, prostaglandin $\mathrm{E}_{2}$ stimulation did not affect mucin exocytosis from goblet cells but appeared to drive fluid loss from columnar cells, which is likely to "wash-out" mucins from the crypts to rest on the luminal surface of the epithelium. Studies on total mucin output from an isolated, vascularly perfused rat colon have noted an increase in the number of cavitated goblet cells following stimulation with cholinergic agonists, prostaglandin $\mathrm{E}_{2}$, and peptide $\mathrm{YY}$ [35]. In further studies using this model, total mucin output (as assessed by ELISA) was also increased in response to the agents used in the previous study [35] as well as serotonin, Vasoactive Intestinal Peptide (VIP), interleukin-1 $\beta$, and NO precursors [36]. While it is not possible to isolate the effect of these factors on, for example, mucin biosynthesis or granular exocytosis within such studies, these data give a strong physiological indicator of drives for increased colonic mucin discharge.

While mostly associated with goblet cell proliferation in the lung, recent studies have suggested a role for the ETS transcription factor SPDEF in intestinal goblet cell proliferation [37, 38]. Similarly, IL-9 has been linked to the lung inflammatory pathologies. In IL-9-overexpressing mice, Muc2 expression (as well as other goblet cell-related genes) was also elevated in the intestine. Knock-out mouse 


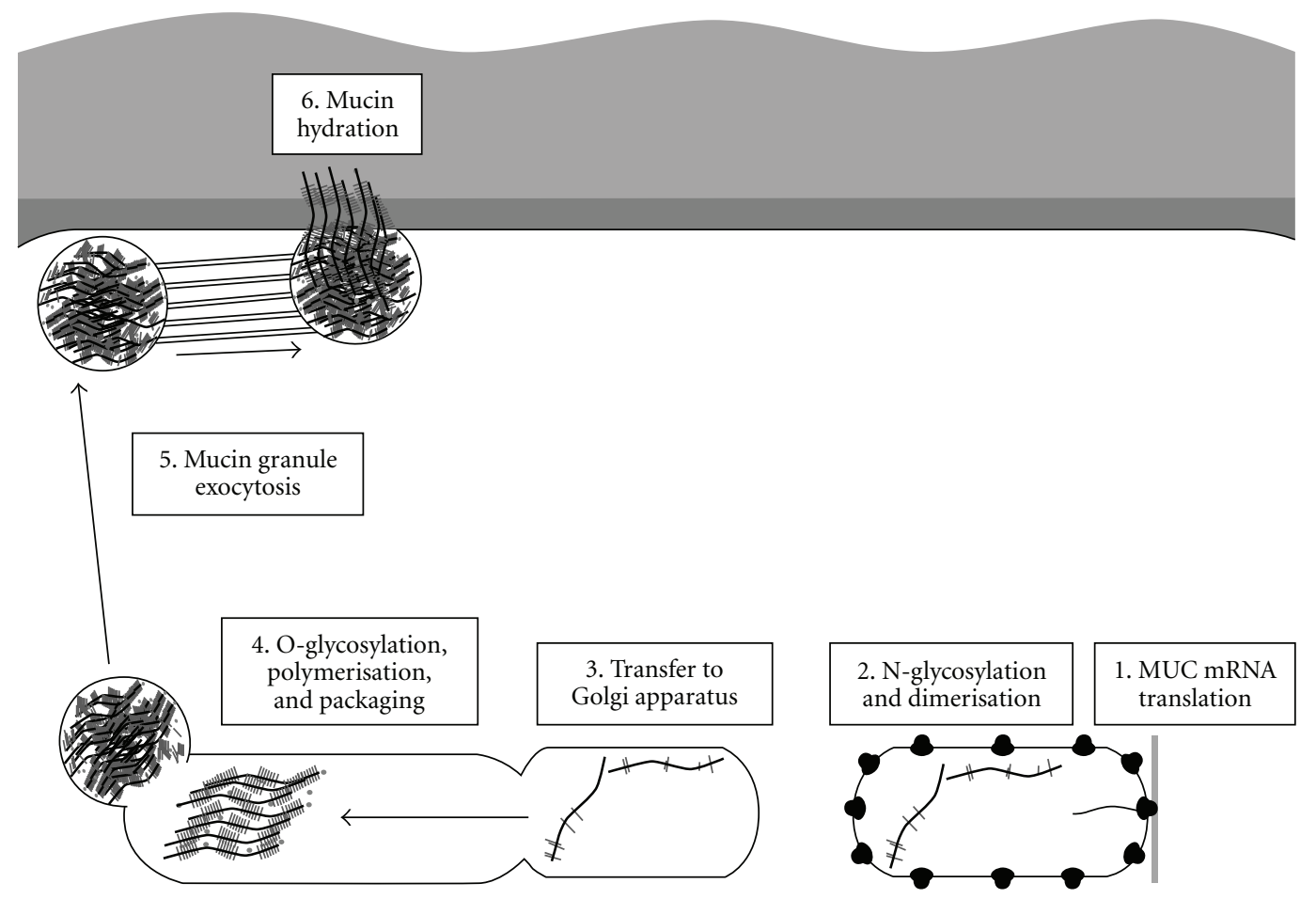

FIGURE 1: Major posttranscriptional steps involved in colonic mucin synthesis and secretion. (1) MUC gene products are translated at the rough endoplasmic reticulum. (2) MUC gene products are then N-glycosylated and dimerised at the C-terminal. (3) The N-glycosylation is necessary for mucins to be transferred to the Golgi apparatus for further processing. Within the Golgi apparatus, mucins are O-glycosylated and polymerised by disulphide bridge formation between cysteine-rich $\mathrm{N}$-terminal sections of the polypeptide backbone. Polymeric mucins become tightly packed due to the presence of high concentrations of calcium ions. (4) The resulting mucin granules are externalised by the goblet cells via exocytosis. (5) Following release, mucin granules rapidly unfurl into a viscoelastic mucus gel bilayer (adapted from details given in $[23,45,46])$.

studies suggested a necessity for the presence of IL-13 for this hypersecretion and goblet cell hyperplasia to occur [39].

In vivo studies would suggest that the colonic mucus barrier is a functional bilayer $[8,40]$. The two layers are rheologically distinct [41]. Upon the application of shear stress, the outer layer of mucus rapidly moves from a gel state to a liquid state. This layer is therefore believed to act as a lubricant and is important in reducing colonic shear stress. As it is constantly removed, this outer layer may also act to return the material back into the centre of the lumen, thereby aiding in the reduction of mucosal exposure to such material [7]. The inner, adherent mucus cannot be removed by suction and is believed to act as a selective physical barrier to the contact of luminal factors with the underlying mucosa, while still allowing absorptive function to occur [42]. Due to the large hydration spheres of mucins in the hydrated mucus gel, it is likely that the mucus gel is imbued with a functional pore size anywhere in the region of $10-500 \mathrm{~nm}$ [43]. Diffusion through these pores will be dependent on the charge of the secreted mucins and the properties of the particle crossing the mucus, as well as the thickness of the mucus layer. Studies assessing the secretion dynamics of these mucus layers in an anaesthetised rat model would suggest that the outer, lubricative mucus layer equilibrates to maximal thicknesses of over $600 \mu \mathrm{m}$, and the shear-resistant inner layer is maintained at approximately $100-200 \mu \mathrm{m}$ in rats fed a standard diet $[8,40,44]$. It must be noted that within these studies, the mucus layer is measured in the absence of normal colonic contents.

\section{The Colonic Mucus Barrier as a Microbial Niche}

The colonic mucus barrier can act as either an energy source, or as a potential support media for growth to the colonic microflora [47]. While a single bacterial species may not possess the necessary enzymes to cleave all the chemical linkages within the mucin structure, it has previously been hypothesised that the ability of each species to thrive as a whole may be dependent on the presence of upstream degradation of mucin by the colonic microbiome. Previous faecal culture studies under anaerobic conditions in mucinagar gels could suggest that enterobacteria and Bacteroides species could be the most predominant within the colonic mucus [48]. However, it must be noted that these studies used gastric mucin as a starting point which has different carbohydrate structures than colonic mucin, which would be expected to affect both bacterial adhesion and degradation.

Due to their proximity to the underlying mucosa, it is likely that the bacteria that populate the colonic mucus 
barrier will have the greatest effect on colonic mucosal responses, including mucus secretion, immunity, and inflammatory responses. However, very little is known about the types of bacteria that inhabit the mucus barrier. Recently, a series of experiments outlined by Johansson et al., (2008) [49] have moved the research in this area forwards. Perhaps the major finding of this work was that within the normal mouse colonic mucus bilayer, bacteria were only found to occur within the outer, lubricative layer and did not occur within the inner adherent layer (as evidenced by 16 s ribosomal RNA in situ hybridisation of histological sections). This would therefore suggest that under normal conditions, the adherent layer is impenetrable to colonic bacteria and that the outer layer could be a major habitat for commensal bacteria.

While colonic mucus acts as both a barrier and a potential niche for the microflora to exploit, it also appears as if the presence of bacteria in the colon is a major drive of both mucus secretion and normal colonic morphology. This is highlighted by the classic histological observation that germ-free animals have a thinner colonic musculature, with shorter colonic crypts alongside a lack of goblet cells and thin mucus layer [50-53]. In normal human development, the colonic microflora begins to develop from parturition due to indirect maternal inoculation [3]. While germ-free conditions are unlikely in either human physiology or pathophysiology, large-scale changes to bacterial numbers or content could greatly affect mucosal protection. In the case of an already deficient mucus layer, increasing numbers of bacteria that are able to degrade proteins would be more likely to cause mucosal damage/infiltration. Temporary reduction of colonic bacterial numbers (e.g., during antibiotic therapy) would be unlikely to cause unwanted mucosal side effects, but in the long term could lead to a less protective mucus barrier.

Studies in knock-out mice have suggested that deletion of the murine MUC2 orthologue Muc2 results in the onset of "spontaneous" (i.e., not chemically induced) colorectal cancer and colitis [54, 55]. Within studies on human colorectal adenoma progression, changes to mucin gene product expression and glycosylation patterns have been noted. The MUC5AC gene product, which is normally secreted in the stomach, but is absent from normal colon, is frequently found in colorectal adenomas and in the area surrounding the adenoma [20]. Mucinous and nonmucinous carcinomas exhibit separate phenotypic changes to mucin gene expression. In the mucinous adenocarcinoma, there is an increased expression of both MUC5AC and MUC2 in comparison to the nonmucinous form [56]. In the nonmucinous carcinoma, there is a reduction in total mucus output, accompanied by a shortening of the mucin oligosaccharide chains [21], particularly through the increased presence of two-residue long GalNAc -sialic acids (Sialyl-Tn antigens) [57]. The change in mucin oligosaccharides is also characterised by a reduction in sulphation levels versus normal mucosa [58] and reduced sialic acid content [59]. The loss of these factors from oligosaccharides results in the reduction of negative charge from the secreted mucin.
Similar losses in sulphation (as well as fucosylation) have also been noted to occur in ulcerative colitis $[21,60,61]$. A reduction in total MUC2 secretion also seems evident in active ulcerative colitis $[62,63]$. As with colorectal cancer, there appears to be an increased expression of MUC5AC in ulcerative colitis $[64,65]$, which both animal and patient studies would suggest be linked to pre- or early neoplastic changes $[66,67]$.

The above evidence highlights that changes to both the protein and carbohydrate portions of secreted mucins occur in the diseased state. Such changes are likely to reduce the protective potential of the colonic mucus gel and may lead to an altering of the available microfloral niche within the secreted mucus, thereby potentially changing the bacterial population.

Recent preliminary metabolic profiling studies have suggested that an increased appearance of cysteine and proline occur in the faecal water extracts of individuals with colorectal cancer compared to controls [68]. Both of these amino acids are found in high amounts in mucins (cysteine is found in globular terminal structures and is necessary for polymerisation whereas proline is found in high amounts in the glycosylated variable number of tandem repeat structures, where it is thought to act as a "spacer" between glycosylated residues (serine or threonine) that imbue the molecule with a greater degree of flexibility). The increased presence of these amino acids would be suggestive of elevated mucolysis, yet would more broadly predict an increase in protein degradation in the colorectal lumen.

Certain bacterial strains appear to have the ability to preferentially target human colonic mucins $[69,70]$. Adhesion to mucins is believed to be driven by the interaction between external bacterial structures and mucin carbohydrate structures. Proteomic analysis of mouse colonic mucus gels demonstrated that Fc-gamma-binding protein was found covalently bound to isolated mucins [71].

16s ribosomal RNA analysis has previously been used to assess global bacterial make-up of the human colonic microflora [72]. In some cases, this technology has been used to assess the occurrence of bacteria within mucosal biopsies (referred to as mucosa-associated bacteria but likely to be a mixture of any bacteria adhered to the mucosa and those associated with the outer and inner mucus layers). Such studies would suggest that the faecal microflora is distinct from that found in mucosal biopsies, with differences occurring in the mucosal biopsy microflora along the length of the large bowel [73], with marked intra-individual variations being also noted [74]. The mucosal biopsy microflora of ulcerative colitis moving from remission to relapse patients was noted to be considerably less stable over time than healthy control individuals in a small cohort study [75]. A wider diversity of the colonic biopsy TM7-bacteria was also recently noted in Crohn's Disease compared to ulcerative colitis patients or controls [76].

It is possible that there is either a direct bacterial degradation of colorectal mucins by colonic bacteria in colorectal mucosal disease or that the presence of certain bacterial species or by-products alters the pathways of mucin biosynthesis and secretion. While the relative ratios of 
constituent bacterial species within the colonic microflora (particularly the relative proportion of Bifidobacteria and Lactobacilli) have been postulated to be of importance to colonic health and disease $[77,78]$, it should be noted that the overall enzymatic spectrum [79] of the microflora or the by-products thereof [80] may be of greater relevance to human health. A number of studies have suggested that there is an increase in the numbers of mucosa-associated bacteria, as reviewed by Strober et al., (2007) [81], although these levels did not necessarily appear to correlate well with mucosal inflammation [82]. There is no consensus on largescale changes of bacterial populations or obvious mucosal infections that occur within IBD [81] or colorectal cancer. Within the case of epithelial damage and/or infiltration, it is likely that bacterial contact with Toll-like receptors could trigger inflammatory and immune responses, including increased mucin secretion [83].

\section{Bacterial By-Products and the Colonic Mucus Barrier}

Although the colonic mucosa is surrounded by a wide variety of potentially damaging agents, the physiological response could be described as a "dampened inflammation" or general tolerance. As previously discussed, an absence of colonic microflora tends to result in a reduction in the standard maturation of the colonic epithelium, as seen in atypical histology. As very few bacteria cross the colonic epithelia (and possibly even the inner adherent mucus barrier) outside of major mucosal trauma, it is unlikely that bacterial presence is having a direct effect on colonic physiology until end-stage mucosal infection. Therefore, many of the effects of bacteria on mucus secretion may be elicited indirectly by bacterial by-products. Previous evidence from experimental models (see below) would support this hypothesis although it must be noted that only a fraction of bacterial by-products have been tested for their potential to affect such processes.

Upon bacterial cell death, lipopolysaccharides (LPS) are shed into the colonic lumen. In germ-free rats, colonic goblet cell numbers increased five days after LPS was applied orally [84]. The level of interleukin-8 (IL-8) and total mucin mRNA levels have also been shown to be significantly elevated in a mucus-producing colonic cell culture study in response to LPS stimulation [85].

Both increased mucin release and increased goblet cell numbers have been reported with direct instillation of low levels of butyrate $(5 \mathrm{mM})$ into a vascularly perfused rat colon model. Higher levels of butyrate (up to $100 \mathrm{mM}$ ) actually lowered the level of mucin secretion whereas the same concentration range of acetate $(5-100 \mathrm{mM})$ increased mucin secretion in a dose-dependent manner and propionate had no effect [86]. Previous studies on mucus secretion dynamics have suggested that low luminal concentrations of butyrate $(7 \mathrm{mM})$ resulted in an increased rate of mucus barrier secretion following removal, but also resulted in a decrease in the maximal mucus thickness attained (see Figure 2) [87]. Similar effects were noted in more recent studies where long-term administration of high butyrate concentrations $(100 \mathrm{mM})$ directly into the mouse colon over a 7 -day period

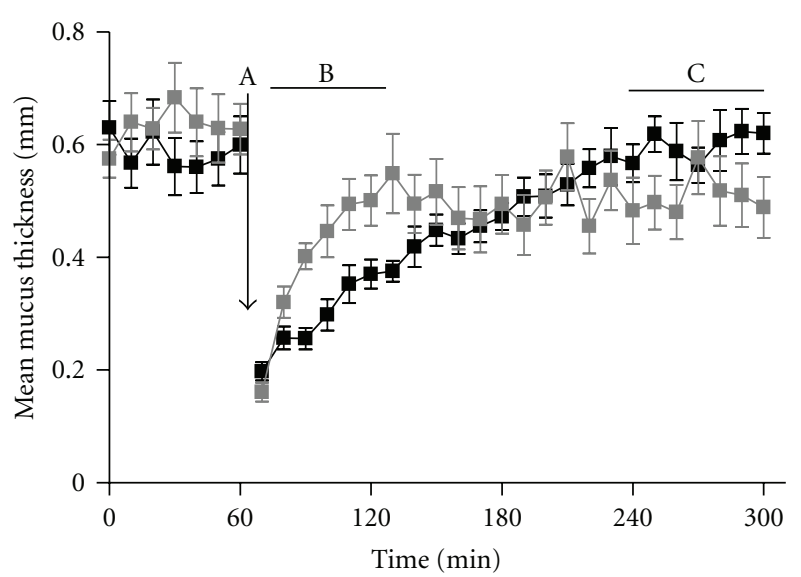

Figure 2: Rat colonic mucus secretion dynamics assessed in the presence of $7 \mathrm{mM}$ butyrate in saline (grey line) and isotonic saline (black line). $N=5$ animals for each treatment. After 60 minutes, the loosely adherent mucus layer is removed by suction (A). Over the subsequent 60 minutes (B), the mucus replenishment rate was approximately three times higher in the presence of butyrate versus the saline control $(P=.0313$ when compared by paired, nonparametric $t$-test). Over the last hour of assessment when the mucus barrier had reached equilibrium (C), the total maximal mucus thickness in the presence of butyrate was significantly lower than the saline control group $(P=.0023$ when compared by unpaired nonparametric $t$-test).

resulted in an upregulation of Muc2 gene expression, but a reduction in the histologically assessed adherent mucus layer was noted [88]. Mechanistic studies have suggested that mucin output [89] and upregulation of MUC2 gene expression [90] are dependent on cholinergic pathways and myofibroblast-derived prostaglandins, respectively.

Reactive oxygen species (ROSs) are a by-product of aerobic respiration that have been shown to occur to millimolar levels in human colonic luminal contents [91]. ROS have been shown to increase mucus secretion rates at low luminal concentrations $\left(5 \mathrm{mM} \mathrm{H}_{2} \mathrm{O}_{2}\right.$ in the presence of $\mathrm{Fe}^{++}$), but lead to mucus degradation and mucosal reddening at higher concentrations ( 25 and $50 \mathrm{mM} \mathrm{H}_{2} \mathrm{O}_{2}$ [42]. These data would suggest that the presence of ROS could be sensed by the colonic mucosa, with the low levels driving the secretion of a more protective mucus barrier. At higher levels, the degradation of mucus, and potential damage of the underlying mucosa, results in degradation of the mucus barrier that outweighs increased secretion.

\section{Summary}

The colonic mucus bilayer acts to reduce shear stress and protect the underlying mucosa from damaging luminal entities while still allowing colonic salvage to occur. As such, the mucus barrier is a key to innate immunity. The colonic mucus barrier represents a window of colorectal health. There is evidence that the MUC gene products secreted are different in the normal state compared to colorectal pathophysiology, such as adenoma formation and ulcerative colitis. 
There are uniquely high numbers of resident bacteria within the large intestine. However, the inner layer of colonic mucus appears to be generally impermeable to this resident microflora and maintains a physical barrier with an exclusion limit of 100 microns between the overlying bacteria and the underlying epithelium. The outer, lubricative mucus layer appears to act as a niche for bacterial population. 16s ribosomal RNA analysis would suggest qualitative differences between the bacterial population that resides within the mucus and that occurring within the lumen (approximated by faecal sampling). It is likely that the bacteria that reside within the mucus will have the greatest impact on the physiology and pathophysiology of the colonic mucosa.

Development of normal colonic morphology, including production of a functionally relevant mucus barrier, is largely driven by the presence of the resident colonic microflora. As bacteria rarely appear to interact directly with the colonic epithelium under normal physiological conditions, it appears likely that the diffusion of bacterial by-products across the colonic mucus barrier to the underlying mucosa acts as a major drive for mucosal maturation and hence affects the processes that govern mucus secretion (mucin synthesis, mucin granule exocytosis, and goblet cell proliferation) Previous evidence notes particular roles for LPS and SCFA in driving mucus secretion.

There is a need for further studies into how fluctuations in specific bacterial populations affect mucin synthesis and secretion, as well as how such populations adhere to or degrade mucus/mucins in a mixed culture. Coassessment of faecal mucins and bacterial populations/bacterial byproducts could be utilised as a noninvasive screening technique in human participants. This methodology may be an indirect route of testing (a) whether changes in the microflora drive changes to mucin secretion/degradation and (b) whether such changes are associated with disease incidence or onset.

\section{References}

[1] M. Bouchoucha, G. Devroede, E. Dorval, A. Faye, P. Arhan, and M. Arsac, "Different segmental transit times in patients with irritable bowel syndrome and "normal" colonic transit time: is there a correlation with symptoms?" Techniques in Coloproctology, vol. 10, no. 4, pp. 287-295, 2006.

[2] R. B. Oliveira, O. Baffa, L. E. A. Troncon, J. R. A. Miranda, and C. R. Cambrea, "Evaluation of a biomagnetic technique for measurement of orocaecal transit time," European Journal of Gastroenterology and Hepatology, vol. 8, no. 5, pp. 491-495, 1996.

[3] C. Edwards, "Physiology of the colorectal barrier," Advanced Drug Delivery Reviews, vol. 28, no. 2, pp. 173-190, 1997.

[4] G. R. Gibson and M. B. Roberfroid, "Dietary modulation of the human colonic microbiota: introducing the concept of prebiotics," Journal of Nutrition, vol. 125, no. 6, pp. 1401-1412, 1995.

[5] K. M. Tuohy, S. Kolida, and G. R. Gibson, "Use of probiotics and prebiotics for improving gut health," Agro Food Industry Hi-Tech, vol. 15, no. 1, pp. 33-35, 2004.

[6] F. Guarner and J.-R. Malagelada, "Gut flora in health and disease," The Lancet, vol. 361, no. 9356, pp. 512-519, 2003.
[7] I. A. Brownlee, M. E. Havler, P. W. Dettmar, A. Allen, and J. P. Pearson, "Colonic mucus: secretion and turnover in relation to dietary fibre intake," Proceedings of the Nutrition Society, vol. 62, no. 1, pp. 245-249, 2003.

[8] C. Atuma, V. Strugala, A. Allen, and L. Holm, "The adherent gastrointestinal mucus gel layer: thickness and physical state in vivo," American Journal of Physiology, vol. 280, no. 5, pp. G922-G929, 2001.

[9] G. T. Macfarlane and S. Macfarlane, "Human colonic microbiota: ecology, physiology and metabolic potential of intestinal bacteria," Scandinavian Journal of Gastroenterology, vol. 32, no. 222, pp. 3-9, 1997.

[10] S. Macfarlane and J. F. Dillon, "Microbial biofilms in the human gastrointestinal tract," Journal of Applied Microbiology, vol. 102, no. 5, pp. 1187-1196, 2007.

[11] L. A. Van Der Waaij, H. J. M. Harmsen, M. Madjipour et al., "Bacterial population analysis of human colon and terminal ileum biopsies with 16S rRNA-based fluorescent probes: commensal bacteria live in suspension and have no direct contact with epithelial cells," Inflammatory Bowel Diseases, vol. 11, no. 10, pp. 865-871, 2005.

[12] A. Matsumura, T. Saito, M. Arakuni, H. Kitazawa, Y. Kawai, and T. Itoh, "New binding assay and preparative trial of cellsurface lectin from Lactobacillus acidophilus group lactic acid bacteria," Journal of Dairy Science, vol. 82, no. 12, pp. 25252529, 1999.

[13] R. Rajkumar, H. Devaraj, and S. Niranjali, "Binding of Shigella to rat and human intestinal mucin," Molecular and Cellular Biochemistry, vol. 178, no. 1-2, pp. 261-268, 1998.

[14] A. W. C. Einerhand, I. B. Renes, M. K. Makkink, M. Van Der Sluis, H. A. Büller, and J. Dekker, "Role of mucins in inflammatory bowel disease: important lessons from experimental models," European Journal of Gastroenterology and Hepatology, vol. 14, no. 7, pp. 757-765, 2002.

[15] J. Dekker, J. W. A. Rossen, H. A. Büller, and A. W. C. Einerhand, "The MUC family: an obituary," Trends in Biochemical Sciences, vol. 27, no. 3, pp. 126-131, 2002.

[16] Y. Chen, Y. H. Zhao, T. B. Kalaslavadi et al., "Genomewide search and identification of a novel gel-forming mucin MUC19/Muc19 in glandular tissues," American Journal of Respiratory Cell and Molecular Biology, vol. 30, no. 2, pp. 155165, 2004.

[17] P. Pigny, V. Guyonnet-Duperat, A. S. Hill et al., "Human mucin genes assigned to $11 \mathrm{p} 15.5$ : identification and organization of a cluster of genes," Genomics, vol. 38, no. 3, pp. 340352, 1996.

[18] J. R. Gum Jr., J. W. Hicks, N. W. Toribara, B. Siddiki, and Y. S. Kim, "Molecular cloning of human intestinal mucin (MUC2) cDNA. Identification of the amino terminus and overall sequence similarity to prepro-von Willebrand factor," Journal of Biological Chemistry, vol. 269, no. 4, pp. 2440-2446, 1994.

[19] A. Allen, D. A. Hutton, and J. P. Pearson, "The MUC2 gene product: a human intestinal mucin," International Journal of Biochemistry and Cell Biology, vol. 30, no. 7, pp. 797-801, 1998.

[20] J. C. Byrd and R. S. Bresalier, "Mucins and mucin binding proteins in colorectal cancer," Cancer and Metastasis Reviews, vol. 23, no. 1-2, pp. 77-99, 2004.

[21] A. P. Corfield, N. Myerscough, R. Longman, P. Sylvester, S. Arul, and M. Pignatelli, "Mucins and mucosal protection in the gastrointestinal tract: new prospects for mucins in the pathology of gastrointestinal disease," Gut, vol. 47, no. 4, pp. 589-594, 2000. 
[22] S. L. Bell, G. Xu, I. A. Khatri, R. Wang, S. Rahman, and J. F. Forstner, "N-linked oligosaccharides play a role in disulphidedependent dimerization of intestinal mucin Muc2," Biochemical Journal, vol. 373, no. 3, pp. 893-900, 2003.

[23] N. Asker, M. A. B. Axelsson, S.-O. Olofsson, and G. C. Hansson, "Dimerization of the human MUC2 mucin in the endoplasmic reticulum is followed by a N-glycosylationdependent transfer of the mono- and dimers to the Golgi apparatus," Journal of Biological Chemistry, vol. 273, no. 30, pp. 18857-18863, 1998.

[24] J. M. H. Larsson, H. Karlsson, H. Sjövall, and G. C. Hansson, "A complex, but uniform O-glycosylation of the human MUC2 mucin from colonic biopsies analyzed by nanoLC/MSn," Glycobiology, vol. 19, no. 7, pp. 756-766, 2009.

[25] K. Godl, M. E. V. Johansson, M. E. Lidell et al., "The N terminus of the MUC2 mucin forms trimers that are held together within a trypsin-resistant core fragment," Journal of Biological Chemistry, vol. 277, no. 49, pp. 47248-47256, 2002.

[26] P. Verdugo, "Goblet cells secretion and mucogenesis," Annual Review of Physiology, vol. 52, pp. 157-176, 1990.

[27] M. Kesimer, A. M. Makhov, J. D. Griffith, P. Verdugo, and J. K. Sheehan, "Unpacking a gel-forming mucin: a view of MUC5B organization after granular release," American Journal of Physiology, vol. 298, no. 1, pp. L15-L22, 2010.

[28] M. A. S. Garcia, N. Yang, and P. M. Quinton, "Normal mouse intestinal mucus release requires cystic fibrosis transmembrane regulator-dependent bicarbonate secretion," Journal of Clinical Investigation, vol. 119, no. 9, pp. 2613-2622, 2009.

[29] P. M. Quinton, "Cystic fibrosis: impaired bicarbonate secretion and mucoviscidosis," The Lancet, vol. 372, no. 9636, pp. 415-417, 2008.

[30] J. Iwashita, Y. Sato, H. Sugaya, N. Takahashi, H. Sasaki, and T. Abe, "mRNA of MUC2 is stimulated by IL-4, IL-13 or TNF- $\alpha$ through a mitogen-activated protein kinase pathway in human colon cancer cells," Immunology and Cell Biology, vol. 81, no. 4, pp. 275-282, 2003.

[31] A. Kanoh, H. Takeuchi, K. Kato, M. Waki, K. Usami, and T. Irimura, "Interleukin-4 induces specific pp-GalNAc-T expression and alterations in mucin O-glycosylation in colonic epithelial cells," Biochimica et Biophysica Acta, vol. 1780, no. 3, pp. 577-584, 2008.

[32] C. K. Heazlewood, M. C. Cook, R. Eri et al., "Aberrant mucin assembly in mice causes endoplasmic reticulum stress and spontaneous inflammation resembling ulcerative colitis," PLoS Medicine, vol. 5, no. 3, article no. e54, pp. 0440-0460, 2008.

[33] N. M.J. Schwerbrock, M. K. Makkink, M. van der Sluis et al., "Interleukin 10-deficient mice exhibit defective colonic Muc2 synthesis before and after induction of colitis by commensal bacteria," Inflammatory Bowel Diseases, vol. 10, no. 6, pp. 811 823, 2004.

[34] D. R. Halm and S. T. Halm, "Secretagogue response of goblet cells and columnar cells in human colonic crypts," American Journal of Physiology, vol. 277, no. 3, pp. C501-C522, 1999.

[35] P. Plaisancié, A. Bosshard, J.-C. Meslin, and J.-C. Cuber, "Colonic mucin discharge by a cholinergic agonist, prostaglandins, and peptide YY in the isolated vascularly perfused rat colon," Digestion, vol. 58, no. 2, pp. 168-175, 1997.

[36] P. Plaisancié, A. Barcelo, F. Moro, J. Claustre, J.-A. Chayvialle, and J.-C. Cuber, "Effects of neurotransmitters, gut hormones, and inflammatory mediators on mucus discharge in rat colon," American Journal of Physiology, vol. 275, no. 5, pp. G1073-G1084, 1998.
[37] T. K. Noah, A. Kazanjian, J. Whitsett, and N. F. Shroyer, "SAM pointed domain ETS factor (SPDEF) regulates terminal differentiation and maturation of intestinal goblet cells," Experimental Cell Research, vol. 316, no. 3, pp. 452-465, 2010.

[38] A. Gregorieff, D. E. Stange, P. Kujala et al., "The Ets-domain transcription factor spdef promotes maturation of goblet and paneth cells in the intestinal epithelium," Gastroenterology, vol. 137, no. 4, article e3, pp. 1333-1345, 2009.

[39] V. Steenwinckel, J. Louahed, M. M. Lemaire et al., "IL9 promotes IL-13-dependent paneth cell hyperplasia and up-regulation of innate immunity mediators in intestinal mucosa," Journal of Immunology, vol. 182, no. 8, pp. 47374743, 2009.

[40] V. Strugala, A. Allen, P. W. Dettmar, and J. P. Pearson, "Colonic mucin: methods of measuring mucus thickness," Proceedings of the Nutrition Society, vol. 62, no. 1, pp. 237-243, 2003.

[41] C. Taylor, A. Allen, P. W. Dettmar, and J. P. Pearson, "Two rheologically different gastric mucus secretions with different putative functions," Biochimica et Biophysica Acta, vol. 1674, no. 2, pp. 131-138, 2004.

[42] I. A. Brownlee, J. Knight, P. W. Dettmar, and J. P. Pearson, "Action of reactive oxygen species on colonic mucus secretions," Free Radical Biology and Medicine, vol. 43, no. 5, pp. 800-808, 2007.

[43] S. K. Lai, D. E. O’Hanlon, S. Harrold et al., "Rapid transport of large polymeric nanoparticles in fresh undiluted human mucus," Proceedings of the National Academy of Sciences of the United States of America, vol. 104, no. 5, pp. 1482-1487, 2007.

[44] I. A. Brownlee, A. Allen, J. P. Pearson et al., "Alginate as a source of dietary fiber," Critical Reviews in Food Science and Nutrition, vol. 45, no. 6, pp. 497-510, 2005.

[45] A. Allen and G. Flemström, "Gastroduodenal mucus bicarbonate barrier: protection against acid and pepsin," American Journal of Physiology, vol. 288, no. 1, pp. C1-C19, 2005.

[46] G. Forstner, "Signal transduction, packaging and secretion of mucins," Annual Review of Physiology, vol. 57, pp. 585-605, 1995.

[47] P. Louis, K. P. Scott, S. H. Duncan, and H. J. Flint, "Understanding the effects of diet on bacterial metabolism in the large intestine," Journal of Applied Microbiology, vol. 102, no. 5, pp. 1197-1208, 2007.

[48] S. Macfarlane, E. J. Woodmansey, and G. T. Macfarlane, "Colonization of mucin by human intestinal bacteria and establishment of biofilm communities in a two-stage continuous culture system," Applied and Environmental Microbiology, vol. 71, no. 11, pp. 7483-7492, 2005.

[49] M. E. V. Johansson, M. Phillipson, J. Petersson, A. Velcich, L. Holm, and G. C. Hansson, "The inner of the two Muc2 mucin-dependent mucus layers in colon is devoid of bacteria," Proceedings of the National Academy of Sciences of the United States of America, vol. 105, no. 39, pp. 15064-15069, 2008.

[50] M. L. Enss, H. Grosse-Siestrup, U. Schmidt-Wittig, and K. Gärtner, "Changes in colonic mucins of germfree rats in response to the introduction of a "normal" rat microbial flora. Rat colonic mucin," Journal of Experimental Animal Science, vol. 35, no. 3, pp. 110-119, 1992.

[51] L. Szentkuti, H. Riedesel, M.-L. Enss, K. Gaertner, and W. Von Engelhardt, "Pre-epithelial mucus layer in the colon of conventional and germ-free rats," Histochemical Journal, vol. 22, no. 9, pp. 491-497, 1990.

[52] R. R. H. Hill, H. M. Cowley, and A. Andremont, "Influence of colonizing micro-flora on the mucin histochemistry of the neonatal mouse colon," Histochemical Journal, vol. 22, no. 2, pp. 102-105, 1990. 
[53] B. E. Gustafsson, "The physiological importance of the colonic microflora," Scandinavian Journal of Gastroenterology, vol. 17, no. 77, pp. 117-131, 1982.

[54] M. Van der Sluis, B. A. E. De Koning, A. C. J. M. De Bruijn et al., "Muc2-deficient mice spontaneously develop colitis, indicating that MUC2 is critical for colonic protection," Gastroenterology, vol. 131, no. 1, pp. 117-129, 2006.

[55] A. Velcich, W. Yang, J. Heyer et al., "Colorectal cancer in mice genetically deficient in the mucin Muc2," Science, vol. 295, no. 5560, pp. 1726-1729, 2002.

[56] M. Melis, J. Hernandez, E. M. Siegel et al., "Gene expression profiling of colorectal mucinous adenocarcinomas," Diseases of the Colon and Rectum, vol. 53, no. 6, pp. 936-943, 2010.

[57] R. S. Bresalier, S. B. Ho, H. L. Schoeppner et al., "Enhanced sialylation of mucin-associated carbohydrate structures in human colon cancer metastasis," Gastroenterology, vol. 110, no. 5, pp. 1354-1367, 1996.

[58] Y. Matsushita, N. Yamamoto, H. Shirahama et al., "Expression of sulfomucins in normal mucosae, colorectal adenocarcinomas, and metastases," Japanese Journal of Cancer Research, vol. 86, no. 11, pp. 1060-1067, 1995.

[59] A. P. Corfield, N. Myerscough, B. F. Warren, P. Durdey, C. Paraskeva, and R. Schauer, "Reduction of sialic acid $\mathrm{O}$-acetylation in human colonic mucins in the adenomacarcinoma sequence," Glycoconjugate Journal, vol. 16, no. 6, pp. 307-317, 1999.

[60] A. P. Corfield, N. Myerscough, M. Gough, I. Brockhausen, R. Schauer, and C. Paraskeva, "Glycosylation patterns of mucins in colonic disease," Biochemical Society Transactions, vol. 23, no. 4, pp. 840-845, 1995.

[61] A. P. Corfield, N. Myerscough, N. Bradfield et al., "Colonic mucins in ulcerative colitis: evidence for loss of sulfation," Glycoconjugate Journal, vol. 13, no. 5, pp. 809-822, 1996.

[62] B. J.-W. Van Klinken, J.-W. G. Van Der Wal, A. Einerhand, H. A. Büller, and J. Dekker, "Sulphation and secretion of the predominant secretory human colonic mucin MUC2 in ulcerative colitis," Gut, vol. 44, no. 3, pp. 387-393, 1999.

[63] K. M. A. J. Tytgat, J.-W. G. Van Der Wal, A. W. C. Einerhand, H. A. Büller, and J. Dekker, "Quantitative analysis of MUC2 synthesis in ulcerative colitis," Biochemical and Biophysical Research Communications, vol. 224, no. 2, pp. 397-405, 1996.

[64] M.-E. Forgue-Lafitte, B. Fabiani, P. P. Levy, N. Maurin, J.-F. Flejou, and J. Bara, "Abnormal expression of M1/MUC5AC mucin in distal colon of patients with diverticulitis, ulcerative colitis and cancer," International Journal of Cancer, vol. 121, no. 7, pp. 1543-1549, 2007.

[65] R. Shaoul, Y. Okada, E. Cutz, and M. A. Marcon, "Colonic expression of MUC2, MUC5AC, and TFF1 in inflammatory bowel disease in children," Journal of Pediatric Gastroenterology and Nutrition, vol. 38, no. 5, pp. 488-493, 2004.

[66] T. C. H. Che, S. François, S. Bouchet, A. Chapel, and M.-E. Forgue-Lafitte, "Early lesions induced in rat colon epithelium by N-methyl-N'-nitro-N-nitrosoguanidine," Tissue and Cell, vol. 42, no. 3, pp. 190-194, 2010.

[67] N. Tatsumi, R. Kushima, M. Vieth et al., "Cytokeratin 7/20 and mucin core protein expression in ulcerative colitis-associated colorectal neoplasms," Virchows Archiv, vol. 448, no. 6, pp. 756-762, 2006.

[68] D. Monleón, J. M. Morales, A. Barrasa, J. A. López, C. Vázquez, and B. Celda, "Metabolite profiling of fecal water extracts from human colorectal cancer," NMR in Biomedicine, vol. 22, no. 3, pp. 342-348, 2009.
[69] H. Uchida, K. Fujitani, Y. Kawai et al., "A new assay using surface plasmon resonance (SPR) to determine binding of the Lactobacillus acidophilus group to human colonic mucin," Bioscience, Biotechnology and Biochemistry, vol. 68, no. 5, pp. 1004-1010, 2004.

[70] P. Sai Sudha, H. Devaraj, and N. Devaraj, "Adherence of shigella dysenteriae 1 to human colonic mucin," Current Microbiology, vol. 42, no. 6, pp. 381-387, 2001.

[71] M. E. V. Johansson, K. A. Thomsson, and G. C. Hansson, "Proteomic analyses of the two mucus layers of the colon barrier reveal that their main component, the Muc2 mucin, is strongly bound to the fcgbp protein," Journal of Proteome Research, vol. 8, no. 7, pp. 3549-3557, 2009.

[72] A. Sghir, G. Gramet, A. Suau, V. Rochet, P. Pochart, and J. Dore, "Quantification of bacterial groups within human fecal flora by oligonucleotide probe hybridization," Applied and Environmental Microbiology, vol. 66, no. 5, pp. 2263-2266, 2000.

[73] P. B. Eckburg, E. M. Bik, C. N. Bernstein et al., "Microbiology: diversity of the human intestinal microbial flora," Science, vol. 308, no. 5728, pp. 1635-1638, 2005.

[74] H. Hayashi, R. Takahashi, T. Nishi, M. Sakamoto, and Y. Benno, "Molecular analysis of jejunal, ileal, caecal and rectosigmoidal human colonic microbiota using 16S rRNA gene libraries and terminal restriction fragment length polymorphism," Journal of Medical Microbiology, vol. 54, no. 11, pp. 1093-1101, 2005.

[75] S. J. Ott, S. Plamondon, A. Hart et al., "Dynamics of the mucosa-associated flora in ulcerative colitis patients during remission and clinical relapse," Journal of Clinical Microbiology, vol. 46, no. 10, pp. 3510-3513, 2008.

[76] T. Kuehbacher, A. Rehman, P. Lepage et al., "Intestinal TM7 bacterial phylogenies in active inflammatory bowel disease," Journal of Medical Microbiology, vol. 57, no. 12, pp. 1569-1576, 2008.

[77] M. B. Roberfroid, "Prebiotics and probiotics: are they functional foods?" American Journal of Clinical Nutrition, vol. 71, no. 6, pp. 1682S-1690S, 2000.

[78] R. E. , L. M. C. Van Lieshout, M. J. Gosselink, and P. Marteau, "Inability of lactobacillus casei strain GG, L. acidophilus, and bifidobacterium bifidum to degrade intestinal mucus glycoproteins," Scandinavian Journal of Gastroenterology, vol. 30, no. 7, pp. 675-680, 1995.

[79] A. M. Roberton, "Roles of endogenous substances and bacteria in colorectal cancer," Mutation Research, vol. 290, no. 1, pp. 71-78, 1993.

[80] R. Hughes and I. R. Rowland, "Metabolic activities of the gut microflora in relation to cancer," Microbial Ecology in Health and Disease, vol. 12, no. 2, pp. 179-185, 2000.

[81] W. Strober, I. Fuss, and P. Mannon, "The fundamental basis of inflammatory bowel disease," Journal of Clinical Investigation, vol. 117, no. 3, pp. 514-521, 2007.

[82] A. Swidsinski, V. Loening-Baucke, F. Theissig et al., "Comparative study of the intestinal mucus barrier in normal and inflamed colon," Gut, vol. 56, no. 3, pp. 343-350, 2007.

[83] M. T. Abreu, "Toll-like receptor signalling in the intestinal epithelium: how bacterial recognition shapes intestinal function," Nature Reviews Immunology, vol. 10, no. 2, pp. 131-143, 2010.

[84] M.-L. Enss, H. Müller, U. Schmidt-Wittig, R. Kownatzki, M. Coenen, and H. J. Hedrich, "Effects of perorally applied endotoxin on colonic mucins of germfree rats," Scandinavian Journal of Gastroenterology, vol. 31, no. 9, pp. 868-874, 1996. 
[85] M. G. Smirnova, L. Guo, J. P. Birchall, and J. P. Pearson, "LPS up-regulates mucin and cytokine mRNA expression and stimulates mucin and cytokine secretion in goblet cells," Cellular Immunology, vol. 221, no. 1, pp. 42-49, 2003.

[86] A. Barcelo, J. Claustre, F. Moro, J.-A. Chayvialle, J.-C. Cuber, and P. Plaisancié, "Mucin secretion is modulated by luminal factors in the isolated vascularly perfused rat colon," Gut, vol. 46, no. 2, pp. 218-224, 2000.

[87] I. A. Brownlee, M. R. Atherton, M. E. Havler, P. W. Dettmar, A. Allen, and J. P. Pearson, "The effect of dietary fibre intake on mucus secretion in the rat colon," Gums and Stabilisers for the Food Industry, vol. 12, pp. 526-534, 2004.

[88] E. Gaudier, M. Rival, M.-P. Buisine, I. Robineau, and C. Hoebler, "Butyrate enemas Upregulate Muc genes expression but decrease adherent mucus thickness in mice colon," Physiological Research, vol. 58, no. 1, pp. 111-119, 2009.

[89] A. Shimotoyodome, S. Meguro, T. Hase, I. Tokimitsu, and T. Sakata, "Sulfated polysaccharides, but not cellulose, increase colonic mucus in rats with loperamide-induced constipation," Digestive Diseases and Sciences, vol. 46, no. 7, pp. 1482-1489, 2001.

[90] L. E. M. Willemsen, M. A. Koetsier, S. J. H. Van Deventer, and E. A. F. Van Tol, "Short chain fatty acids stimulate epithelial mucin 2 expression through differential effects on prostaglandin E1 and E2 production by intestinal myofibroblasts," Gut, vol. 52, no. 10, pp. 1442-1447, 2003.

[91] J. G. Erhardt, S. S. Lim, J. C. Bode, and C. Bode, "A diet rich in fat and poor in dietary fiber increases the in vitro formation of reactive oxygen species in human feces," Journal of Nutrition, vol. 127, no. 5, pp. 706-709, 1997. 


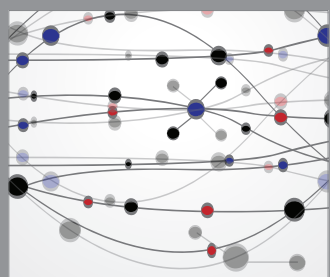

The Scientific World Journal
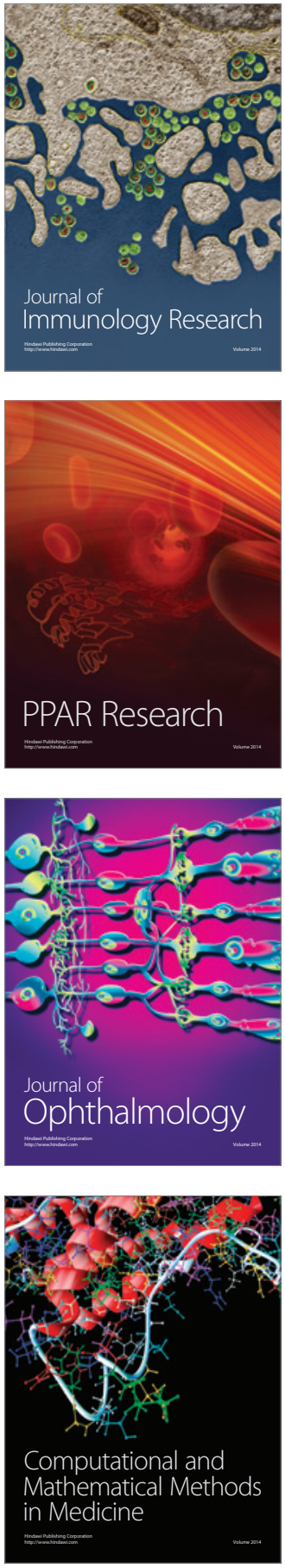

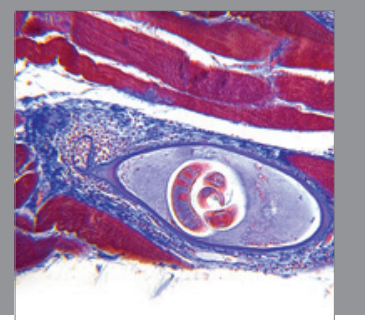

Gastroenterology

Research and Practice
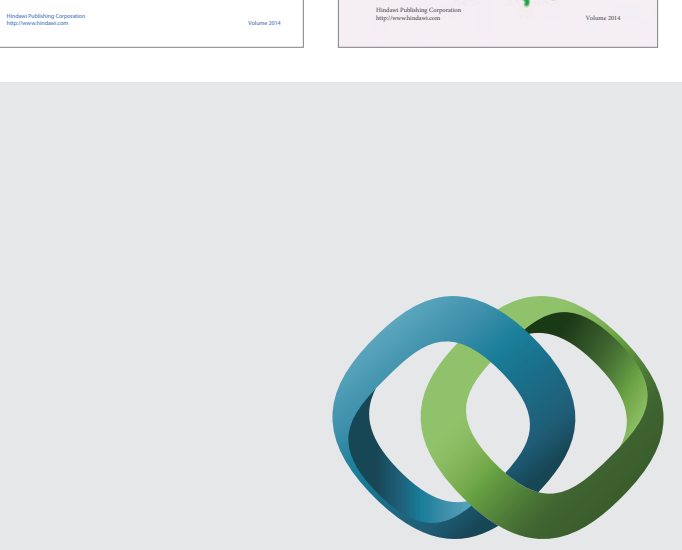

\section{Hindawi}

Submit your manuscripts at

http://www.hindawi.com
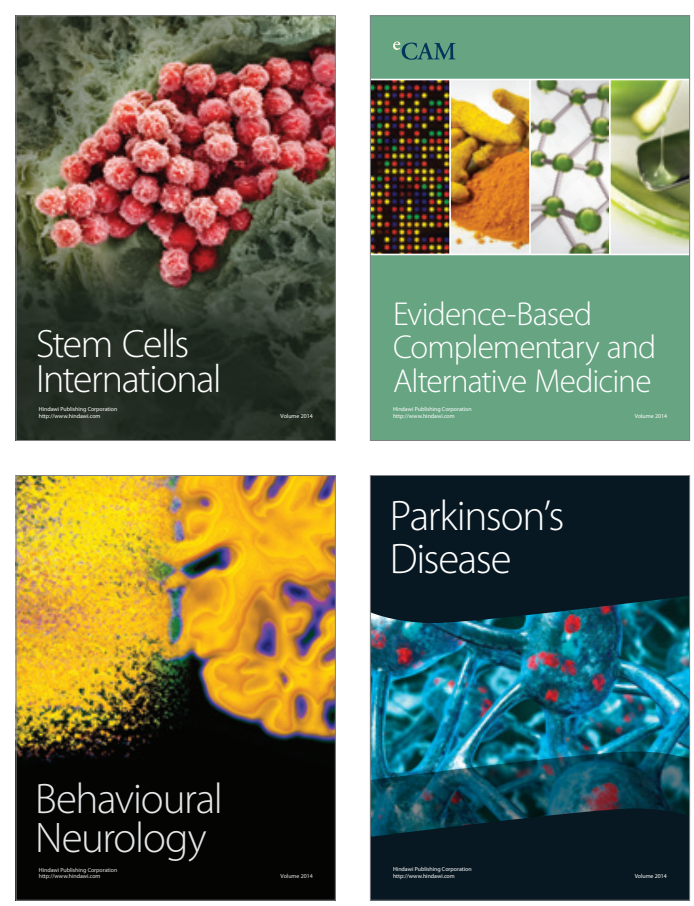

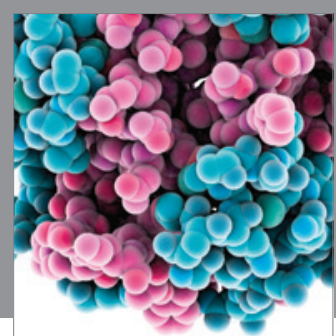

Journal of
Diabetes Research

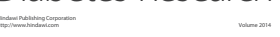

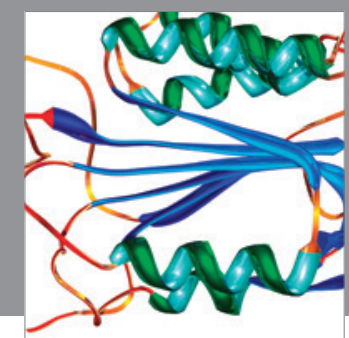

Disease Markers
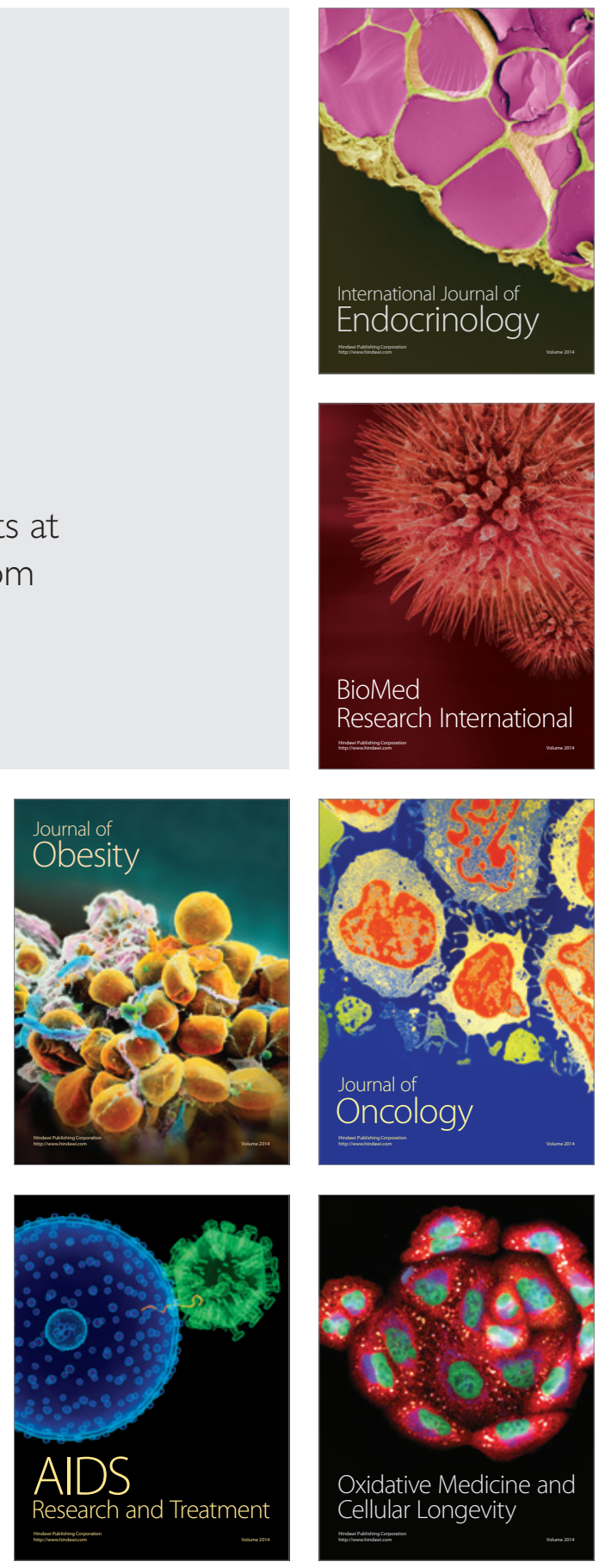